Marcelo Domingues de FARIA ${ }^{1}$

Carlos Eduardo SEYFERT ${ }^{2}$

\section{Dimensões, massa e volume do baço em tartarugas (Trachemys scrypta elegans, Wied,1839)}

\author{
1 - Colegiado Acadêmico de Medicina Veterinária da Universidade Federal do Vale \\ do São Francisco, Petrolina-PE \\ 2 - Instituto de Ciências Biomédicas da Universidade de São Paulo, São Paulo-SP
}

Correspondência para:

Marcelo Domingues de Faria, Univasf Laboratório de Anatomia da Fazenda Experimental, RodoviaBR $407, \mathrm{~km} 12$ - Lote $543, \mathrm{~s} / \mathrm{n}^{\circ}$ - Projeto de Irrigação Senador Nilo Coelho-C1, 56300-990 - Petrolina - PE

Recebido para publicação: 20/07/2006 Aprovado para publicação: 28/08/2008

\title{
Resumo
}

O objetivo deste estudo foi verificar as dimensões, massa e volume do baço em tartarugas (Trachemys scripta elegans WIED, 1839) estabelecendo correlação com as dimensões, massa e volume corporais. Para a confecção deste trabalho, utilizou-se vinte animais, provenientes do Instituto de Psicologia da Universidade de São Paulo, coletados após a eutanásia que, levados ao Laboratório de Anatomia da Faculdade de Medicina Veterinária e Zootecnia da mesma universidade, tiveram suas dimensões, massa e volume corporais aferidos. Então, retirou-se o plastrão, expondo sua cavidade celomática, removendo o baço para realizar as mensurações. Apesar dos animais terem sido criados num mesmo ambiente, sob as mesmas condições ambientais e abatidos no mesmo período do ano, concluiu-se que não há correlação entre as dimensões do baço e as dimensões corporais, onde, animais menores podem apresentar o baço com maiores proporções do que tartarugas maiores, variando conforme as condições individuais fato que ocorre com as demais espécies animais.

\section{Introdução}

Uma vez que cresce o número de adeptos à criação de animais silvestres e selvagens, tanto para fins comerciais e de produção como para criação como animal de companhia e estimação, torna-se imprescindível o conhecimento pormenorizado dos diversos órgãos e sistemas destes animais, com o objetivo de estabelecer padrões particulares de cada espécie, possibilitando a comparação interespecífica, sejam elas de animais domésticos ou até mesmo, entre outros animais silvestres, o que facilitará aos profissionais trabalharem com maior discernimento e entenderam os aspectos anatômicos, servindo como base tanto para clínica como para cirurgia e até mesmo como animais utilizáveis nos diversos fins científicos e experimentais.

Segundo Mota ${ }^{1}$, o baço constitui o maior acúmulo de tecido linfóide do organismo interposto na circulação sanguínea, diferindo-se dos linfonodos e da Bursa de
Fabricius por não ser parte integrante da circulação linfática, pelos tipos celulares que produz, e pelas características macro e microscópicas que possui.

Estudando sobre imunidade dos répteis, Glinsk e Buczek ${ }^{2}$ descrevem que o baço, juntamente com a medula óssea, com o timo, com os tecidos linfóides intestinais e com a bursa cloacal, constituem o sistema de produção de células de defesa desses animais, sendo responsáveis pela produção de células fagocíticas e de células produtoras de anticorpos.

Dulzetto $^{3}$, Faria ${ }^{4}$, Hyman $^{5}$, Mader $^{6}$, Orr ${ }^{7}$, Pisanó e Barbieri ${ }^{8}$, Zapata, Leceta e Barrutia ${ }^{9}$ relatam que o baço de tartarugas apresenta-se como um órgão vermelho escuro arroxeado ou até mesmo amarronzado. Com relação à forma do baço, Ashley ${ }^{10}$, Dulzetto ${ }^{3}$, Hyman $^{5}$ e Mader ${ }^{6}$ descrevem que pode variar de esferóide a elipsóide; já, Sayles ${ }^{11}$ e Zapata, Leceta e Barrutia9 o descrevem como um órgão oval.

Conforme descreve Faria ${ }^{4}$, o baço de 
tartarugas está localizado dorsalmente ao cólon transverso, disposto no plano dorso-medio-lateral esquerdo, podendo estar posicionado caudalmente ao cólon transverso, perdendo a intimidade com o ventrículo gástrico; ou cranialmente ao cólon transverso, com grande contato com o ventrículo gástrico através do ligamento gastrolienal.

\section{Material e Método}

Foram utilizadas 20 tartarugas da espécie Trachemys scripta elegans (WIED, 1839 apud ERNEST: BARBOUR ${ }^{12}$, 1989, p. 204), sendo oito machos e doze fêmeas, doadas pelo Departamento de Psicologia Experimental do Instituto de Psicologia da Universidade de São Paulo.

Após a eutanásia, as tartarugas foram conduzidas ao Laboratório de Anatomia dos Animais Domésticos da Faculdade de Medicina Veterinária e Zootecnia da Universidade de São Paulo, onde se determinou a massa, utilizando balança analítica de precisão digital $\left(\right.$ Plenna $\left.^{\circledR}\right)$, as dimensões (crânio-caudalmente, da placa nucal à placa pigal, e latero-lateralmente) mensuradas com o uso de paquímetro (Vonder ${ }^{\circledR}$ ) e o volume corporal calculado (utilizando o método de Scherle $^{13}$ - descrito mais adiante). Em seguida, o plastrão foi retirado, utilizando-se serra circular sobre as placas periféricas ventrais laterais, visualizando-se a cavidade celomática, e removeu-se o baço, a fim de, mensura-lo com o uso de paquímetro $\left(\right.$ Vonder $\left.^{\circledR}\right)$ e pesa-lo em balança analítica de precisão digital $\left(\right.$ Plenna $\left.{ }^{\circledR}\right)$.

Para determinar o volume dos baços, empregou-se o método de Scherle ${ }^{13}$, que permite que o mesmo seja verificado através do deslocamento de água causado pelo material a ser avaliado sobre balança analítica de precisão digital $\left(P l e n n a^{\circledR}\right)$, sendo que $1 \mathrm{ml}$ equivale a $1 \mathrm{~cm}^{3}$.

Subsequentemente, os dados foram anotados e uma tabela foi confeccionada com os resultados obtidos.

Com relação à nomenclatura utilizada, adotou-se a Nomina Avium ${ }^{14}$, por não haver nomenclatura específica para quelônios, uma vez que, na escala evolutiva, os répteis assemelham-se muito mais às aves do que aos mamíferos.

\section{Resultados, Discussão e Conclusão}

Os animais utilizados neste estudo pertenciam a um único criatório, sendo submetidos ao mesmo tipo de tratamento e condições ambientais e climáticos e, ainda, foram abatidos numa mesma época do ano: fatores que diminuem a disparidade de informações entre os indivíduos. Contudo, animais de idades distintas foram utilizados.

No que concerne à bioscopia do baço, foi notado que o mesmo pode mostrar-se de circular à oval, corroborando os relatos de Dulzetto $^{3}$, Hyman $^{5}$, Mader ${ }^{6}$, Zapata, Leceta e Barrutia ${ }^{9}$, Ashley ${ }^{10} \mathrm{eSayles}^{11}$.Já, no que diz respeito à coloração do baço, o mesmo é apresentado de vermelho escuro a arroxeado, conforme descrito por Dulzetto ${ }^{3}$, Faria ${ }^{4}$, Hyman $^{5}$, Mader $^{6}$, Orr ${ }^{7}$, Pisanó e Barbieri ${ }^{8}$, Zapata, Leceta e Barrutia9.

Com relação aos dados corporais dos animais e as observações lienais, compilou-se as dimensões, a massa e o volume nas tabelas 1 e 2 , respectivamente.

Confrontando os dados numéricos corporais e os dados numéricos dos baços das tartarugas (Quadro 1), nota-se que a correlação é baixa, pois, estatisticamente, as correlações que distanciam-se de 1 são fracamente ligadas (programa BioEstat 3.0 para correlação de Pearson). Com isso, conclui-se que a massa, o volume e as dimensões do baço independem das proporções corporais de tartarugas, sendo que animais com dimensões corporais menores podem apresentar baços com maiores proporções.

\begin{tabular}{|c|c|c|c|c|c|}
\hline & Massa & Volume & Comprimento & Largura & Espessura \\
\hline $\begin{array}{c}\text { Correlação de } \\
\text { Pearson }\end{array}$ & 0,2383 & 0,5473 & 0,4099 & 0,5596 & 0,2121 \\
\hline
\end{tabular}

Quadro 1 - Representação dos níveis de correlação das proporções corporais com as proporções dos baços em tartarugas, utilizando o método de Pearson - São Paulo, 2006 
Tabela 1 - Massa, volume e dimensões corporais dos animais estudados - São Paulo, 2006

\begin{tabular}{cccccc}
\hline Tartaruga & Massa $(\mathrm{g})$ & Volume $\left(\mathrm{cm}^{3}\right)$ & Comprimento $(\mathrm{cm})$ & Largura $(\mathrm{cm})$ & Altura $(\mathrm{cm})$ \\
\hline 1 & 621 & 570 & 17,2 & 12,1 & 5,8 \\
2 & 417 & 400 & 15,7 & 11,5 & 5,0 \\
3 & 529 & 540 & 15,5 & 12,0 & 5,6 \\
4 & 455 & 450 & 14,4 & 10,8 & 5,8 \\
5 & 446 & 500 & 15,4 & 11,5 & 5,3 \\
6 & 764 & 550 & 17,5 & 13,0 & 6,9 \\
7 & 517 & 560 & 16,0 & 12,5 & 5,4 \\
8 & 1422 & 1420 & 22,0 & 17,5 & 7,6 \\
9 & 150 & 180 & 10,8 & 8,5 & 3,9 \\
10 & 395 & 380 & 14,0 & 11,0 & 5,2 \\
11 & 732 & 784 & 17,0 & 13,0 & 7,0 \\
12 & 822 & 780 & 17,5 & 14,0 & 7,2 \\
13 & 214 & 220 & 11,5 & 9,5 & 4,4 \\
14 & 221 & 275 & 11,5 & 9,8 & 4,3 \\
15 & 710 & 1200 & 17,8 & 12,9 & 7,2 \\
16 & 605 & 1140 & 16,3 & 12,5 & 6,0 \\
17 & 368 & 400 & 13,9 & 10,7 & 5,1 \\
18 & 963 & 850 & 19,7 & 14,0 & 6,6 \\
19 & 420 & 410 & 14,2 & 11,2 & 5,2 \\
20 & 270 & 300 & 12,7 & 10,0 & 4,5 \\
\hline Média & 554,75 & 595,45 & 15,53 & 11,9 & 5,7 \\
\hline Mediana & 492 & 595,45 & 15,6 & 11,75 & 5,5 \\
\hline Desvio Padrão & 298,16 & 338,29 & 2,80 & 1,08 \\
\hline & & & & & \\
\hline
\end{tabular}

Spleen dimensions, mass and volume in turtles (Trachemys scrypta elegans, wied,1839)

\section{Abstract}

The purpose of this study was to stabilish the spleen dimensions (lenght, width e thickness), mass and volume of turtle (Trachemys scripta elegans WIED, 1839). We used twenty animals from Instituto de Psicologia of Universidade de São Paulo, collected after euthanasia and were taken to the Anatomy Laboratory of the Faculdade de Medicina Veterinária e Zootecnia at the same university. The corporal mass, volume and dimensions of the animals were taken. Then, the carapace was deduct and the spleen was removed for measurements. Despite the animals have been raised in the same place, under the same environment conditions and have been slaughtered at the same period of the year, we noticed that there isn't any correlation between the spleen dimensions and the corporal dimensions, where, smaller animals can show their spleens in larger dimensions than big turtles, at the depends of individual conditions.
Key-words:

Turtle.

Spleen.

Dimensions.

Mass.

Volume. 
Tabela 2 - Massa, volume e dimensões do baço de tartarugas estudadas - São Paulo, 2006

\begin{tabular}{cccccc}
\hline Tartaruga & Massa $(\mathrm{g})$ & Volume $\left(\mathrm{cm}^{3}\right)$ & Comprimento $(\mathrm{cm})$ & Largura $(\mathrm{cm})$ & Espessura $(\mathrm{cm})$ \\
\hline 1 & 0,94 & 1,0 & 1,7 & 1,3 & 1,1 \\
2 & 0,24 & 0,2 & 1,4 & 0,7 & 0,4 \\
3 & 0,46 & 0,4 & 1,4 & 1,4 & 0,6 \\
4 & 0,49 & 0,7 & 1,4 & 1,4 & 0,4 \\
5 & 0,34 & 0,4 & 1,3 & 1,3 & 0,6 \\
6 & 0,62 & 0,6 & 1,5 & 1,1 & 0,6 \\
7 & 0,53 & 0,6 & 1,5 & 1,2 & 0,7 \\
8 & 0,52 & 0,6 & 1,6 & 1,1 & 0,7 \\
9 & 0,2 & 0,2 & 1,4 & 0,6 & 0,5 \\
10 & 0,53 & 0,4 & 1,5 & 1,1 & 0,6 \\
11 & 0,76 & 0,9 & 1,8 & 1,4 & 0,7 \\
12 & 1,16 & 1,4 & 2,0 & 1,4 & 0,9 \\
13 & 0,2 & 0,1 & 1,0 & 0,7 & 0,4 \\
14 & 0,24 & 0,4 & 1,3 & 1 & 0,4 \\
15 & 1,09 & 1,2 & 1,7 & 1,4 & 1,0 \\
16 & 0,78 & 1,0 & 1,9 & 1,3 & 0,7 \\
17 & 0,93 & 0,1 & 1,3 & 0,7 & 0,5 \\
18 & 0,98 & 1,0 & 2,0 & 1,2 & 0,8 \\
19 & 0,79 & 0,8 & 1,5 & 1,5 & 0,6 \\
20 & 0,29 & 0,4 & 0,9 & 0,9 & 0,6 \\
\hline Média & 0,60 & 0,62 & 1,51 & 1,14 & 0,64 \\
\hline Mediana & 0,53 & 0,6 & 1,5 & 0,28 & 0,6 \\
\hline Desvio Padrão & 0,31 & 0,37 & 0,29 & & \\
\hline
\end{tabular}

\section{Referências}

1 DULZETTO, F. Anatomia comparata dei vertebrati. Bologna: Calderini, 1967. v. 1, p. 1180.

2 GLINSKI, Z.; BUCZEK, J. Aspects of reptile immunity. Medycyna-Weterynaryjna, v. 55, n. 9, p. 574-578, 1999.

3 MOTA, I. Imunologia celular: tecidos e órgãos linfóides. In: MOTA, I. Imunologia básica e aplicada. 4. ed. Rio de Janeiro: Guanabara Koogan, 1989. cap. 1, p. 19-22.

4 FARIA, M. D. A topografia e a irrigação do baço em tartarugas (Trachemys scripta elegans, WIED, 1839). 2003. 85 f. Dissertação (Mestrado em Anatomia dos Animais Domésticos) - Faculdade de Medicina Veterinária e Zootecnia, Universidade de São Paulo, São Paulo, 2003.

5 HYMAN, L. H. Comparative vertebrate anatomy. 2. ed. Chicago: The University of Chicago Press, 1942. p. 277.

6 MADER, D. R. Reptile medicine and surgery. Philadelphia: W. B. Saunders, 1996. p. 280.

7 ORR, R. T. Biologia dos vertebrados. 5. ed. São Paulo: Roca, 1999. p. 107-109.

8 PISANÓ, A.; BARBIERI, F. D. Anatomia comparada de los vertebrados. Buenos Aires: Rivadavia, 1967. p. 170-171, 200-201.

9 ZAPATA, A.; LECETA, J.; BARRUTIA, M. G. Ultrastructure of splenic with pulp of the turtle, Mauremys caspica. Cell and Tissue Research, n. 220, p. 845-855, 1981.

10 ASHLEY, L. M. Laboratory anatomy of the turtle. 6. ed. Washington: College Place, 1969. p. 19-20, 30, 3435 .

11 SAYLES, L. P. Manual for comparative anatomy. New York: MacMillan, 1938. p. 144.

12 ERNST, C. H.; BARBOUR, R. W. Turtles of the world. Washington: Smithsonian Institution Press, 1989. p. 204-206.

13 SCHERLE, W. A simple method for volumetry of organs in quantitative stereology. Mikroskopie, v. 26, p. 57-63, 1970.

14 INTERNATIONAL COMMITTEE ON VETERINARY GROSS ANATOMICAL NOMENCLATURE. Nomina anatomica veterinária. 4. ed. Ithaca: World Association and Veterinary Anatomists, 1994. Together with Nomina histológica, 2nd ed., 1992 and Nomina embriologica veterinaria, 1992. 